\title{
IMPACT OF EXCIPIENTS ON PHARMACEUTICAL AVAILABILITY OF FOLIC ACID FROM TABLETS
}

\author{
ANETA OSTRÓŻKA-CIEŚLIK ${ }^{1 *}$, BARBARA DOLIŃSKA ${ }^{1,2}$ and FLORIAN RYSZKA²
}

${ }^{1}$ Department of Pharmaceutical Technology, Medical University of Silesia in Katowice, School of Pharmacy with the Division of Laboratory Medicine in Sosnowiec, Kasztanowa 3, 41-200 Sosnowiec, Poland

2"Biochefa" Pharmaceutical Research and Production Plant, Kasztanowa 3, 41-200 Sosnowiec, Poland

\begin{abstract}
The impact of excipients contained in individual formulations on the pharmaceutical availability of folic acid was investigated. The release rate of the active substance and the disintegration time of the tablets were analyzed. It has been found that in the presence of sorbitol, glucose and starch, $100 \%$ of folic acid is released within $60 \mathrm{~min}$, and in the presence of lactose and starch $-95 \%$, and the release rates for them are $0.0717 \mathrm{~min}^{-1}$ and $0.0555 \mathrm{~min}^{-1}$ respectively.
\end{abstract}

Keywords: folic acid, dietary supplements, dissolution testing

Folic acid is one of the B vitamins and it is essential for the proper functioning of the human body. It is involved in the synthesis of nucleic acids, the metabolism of amino acids and DNA methylation. It affects the proper functioning of the nervous, cardiovascular, respiratory and hematopoietic systems. It plays an important role in the metabolism of homocysteine. In pregnant women, it reduces the risk of neural tube defects in their offspring by $70 \%$. It is used in the treatment and prevention of megaloblastic anemia, nonspecific inflammation of the bowel, depression and organogenesis disorders. It may reduce the risk of cerebral stroke in people with arterial hypertension (1-6). Estimated average requirement (EAR) for folic acid to be taken by men and women over 19 years of age is $320 \mathrm{mcg}$ per day, and for pregnant women, it is $520 \mathrm{mcg}$ per day. Recommended daily allowance (RDA) for men and women over 19 years of age should be $400 \mathrm{mcg}$ per day, while in the group of pregnant women, it should be $600 \mathrm{mcg}$ per day (7). Dietary supplements are applied to complement the diet and satisfy the increased nutritional needs of women at childbearing age.

Therefore, the purpose of the study was to assess the pharmaceutical availability of folic acid from the developed formulation compared to market preparations. The analysis of the impact of excipi- ents on the pharmaceutical availability of folic acid was of particular importance.

\section{EXPERIMENTAL}

Tablets with folic acid (formulation F-A) were prepared. The powdered ingredients of the tablet mass were sieved through a sieve of $0.8 \mathrm{~mm}$ mesh size and thoroughly mixed in a mortar and then rehomogenized through the $0.8 \mathrm{~mm}$ sieve. Direct compression tableting on punches with a diameter of 12 $\mathrm{mm}$ was used to compress the tablet mass in the Korsch tablet press (Erweka type Eko, Germany). The tablets were compressed at a rate of 3600 tablets / hour. All substances met the requirements of the relevant standards and Polish Pharmacopoeia X and were of recognized analytical grade.

Analysis of the properties of powder mixtures and reference tablets was carried out in accordance with the recommendations of the Polish Pharmacopoeia $X(8,9)$. Their quality was assessed using the volumeter JEL STAV II (J.Engelsmann AG, Germany), moisture analyzer WS 30 ( Radwag, Poland), tablet hardness tester MT 50 (Pharmatron, Switzerland) and friabilator (ZDM, Polfa, Poland).

Three dietary supplements in tablet form with unmodified release profile (marked with symbols

* Corresponding author: e-mail: aostrozka@sum.edu.pl 
Table 1. Composition of dietary supplements containing folic acid.

\begin{tabular}{|c|c|c|c|c|}
\hline Composition & F-A (reference) & F-B & F-C & F-D \\
\hline $\begin{array}{l}\text { Declared content of folic acid } \\
\text { in the dietary supplements }[\mu \mathrm{g}]\end{array}$ & 400 & 400 & 400 & 400 \\
\hline $\begin{array}{l}\text { The average content of folic } \\
\text { acid per tablet }[\mu \mathrm{g}]\end{array}$ & $410 *$ & 390 & $410 *$ & 390 \\
\hline \multicolumn{5}{|l|}{ Pharmaceutical excipients: } \\
\hline Sorbitol & + & - & - & - \\
\hline Glucose & + & - & - & - \\
\hline Lactose & - & - & - & + \\
\hline Potato starch & + & - & - & + \\
\hline Cellulose & - & + & + & + \\
\hline Silicon dioxide & - & + & + & + \\
\hline Magnesium stearate & + & + & + & + \\
\hline
\end{tabular}

*Current pharmacopoeial regulations permit up to $10-25 \%$ of excessive medicinal substance in drugs prone to degradation (e.g. vitamins)

Table 2. Physical characteristics of the powders mixture.

\begin{tabular}{|l|c|}
\hline \multicolumn{2}{|c|}{ Physical characteristics } \\
\hline Bulk density $[\mathrm{g} / \mathrm{mL}]$ & 0.6425 \\
\hline Tap density $[\mathrm{g} / \mathrm{mL}]$ & 0.7908 \\
\hline Hausner's coefficient $(\mathrm{HR})$ & 1.23 \\
\hline Carr's index $\left(\mathrm{I}_{\text {Carr }}\right)$ & 18.75 \\
\hline Moisture content $[\%]$ & 3.7 \\
\hline
\end{tabular}

F-B, F-C, F-D) were included in the study. The composition of tablets is provided in Table 1.

6 tablets of each formulation were taken to study the disintegration time. The analysis was performed on a DisiTest20 apparatus (Sotax, Switzerland) in water at $37 \pm 2^{\circ} \mathrm{C}$ under a roller disk load within $15 \mathrm{~min}$. The analyses were performed in 3 replications.

The amount of folic acid in the tablet and the amount of released folic acid were determined by spectrophotometric method at $\lambda=282$ nm (10) (Cecil CE 302 UV-VIS spectrophotometer, Instrument Cheminst, Poland). The standard curve of the absorbance relation was calculated as a function of the concentration of standard solutions described by the equation $\mathrm{y}=0.0655 \mathrm{x}$. The determination factor was $\mathrm{R}^{2}=0.9995$, and the linear regression error $-3.371 \times 10^{4}$. The sensitivity of the method was $2.69 \times 10^{4} \mathrm{~L} \times \mathrm{mol}^{-1} \times$ $\mathrm{cm}^{-1}$. The precision of the method was positively assessed based on the standard deviation, relative standard deviation, and variation coefficient of the method.
The active substance release test was performed in a rotary vane (DT 600, ERWEKA GmbH, Germany) at $\mathrm{T}=37^{\circ} \mathrm{C} \pm 0.5^{\circ} \mathrm{C}$ for up to $360 \mathrm{~min}$ at $50 \mathrm{rpm}$ using $500 \mathrm{~mL}( \pm 1 \%)$ of phosphate buffer ( $\mathrm{pH}=7.4$ ). For each formulation, 3 series of tests were performed, each time using 24 tablets (4 tablets in each thimble). The percentage of released folic acid per unit of time was determined and release profiles were plotted. The rate of folic acid release from the test formulations was calculated by determining the order of release, release rate constants $\mathrm{k}$ $\left[\mathrm{min}^{-1}\right]$ and half time of release $\mathrm{t}_{50 \%}[\mathrm{~min}]$. The area under the release curve $\left(\mathrm{AUC}_{0-6 \mathrm{~h}}\right)$ describing the percentage of the released drug over time was calculated using the trapezoidal integration algorithm.

Analysis of the effect of the qualitative composition of the formulation on the folic acid release profile was based on the information on the package and compared to the resulting formulation F-A (reference). Differences in the release profile between the formulations were evaluated by calculating the coefficients of similarity (f2) and difference (f1) $(11,12)$. Computations were made using the Statistica program "Pharmaceutical kit: Release profiles" - version 2.7 (StatSoft Poland Sp. Z o.o.).

KinetDS 3.0 Rev. 2010 software was used for the analysis of folic acid dissolution kinetics (13). The table shows the parameters of matching zero-order and first-order kinetic models to the release data: determination factor $\left(\mathrm{R}^{2}\right)$, root mean square error (RMSE) and Akaike information criterion (AIC). The best model of active ingredient release kinetics is characterized by the highest $\mathrm{R}^{2}$ (ideally in the range from 0.970 to 1 ), the lowest RMSE and the lowest AIC $(14,15)$. 
Table 3. Morphological parameters of the references tablets.

\begin{tabular}{|c|c|c|}
\hline \multicolumn{2}{|c|}{ Physical parameters of Formulation F-A } & Norm \\
\hline Mean tablet mass $[\mathrm{mg}] \pm \mathrm{RSD} \% ;(\mathrm{n}=20)$ & $498 \pm 0.45$ & $500 \pm 5.0$ \\
\hline Mean tablet diameter $[\mathrm{mm}] \pm \mathrm{RSD} \% ;(\mathrm{n}=20)$ & $12.14 \pm 0.21$ & \pm 5.0 \\
\hline Mean tablet height $[\mathrm{mm}] \pm \mathrm{RSD} \% ;(\mathrm{n}=20)$ & $5.10 \pm 2.03$ & - \\
\hline Mean tablet density $\left[\mathrm{g} / \mathrm{cm}^{3}\right]$ & 0.844 & - \\
\hline Mean tablet surface $\left[\mathrm{cm}^{2}\right]$ & 4.258 & $<1.0$ \\
\hline Abrasiveness $[\%]$ & 0.7 & $>98^{*} 10^{4} \mathrm{~N} / \mathrm{m}^{2}$ \\
\hline
\end{tabular}

Table 4. Disintegration time of the test formulations.

\begin{tabular}{|c|c|c|}
\hline Formulation type & Acceptance criterion & Disintegration time [min] \\
\cline { 1 - 1 } F-A (reference) & Uncoated tablets for internal & $<15$ \\
\cline { 1 - 1 } F-B & $\begin{array}{c}\text { use should disintegrate in water } \\
\text { at } \mathrm{T}=37^{\circ} \mathrm{C} \text { within up to } 15 \mathrm{~min}\end{array}$ & $<15$ \\
\cline { 1 - 1 } F-C & according to FPX & $>15$ \\
\cline { 1 - 1 } F-D & &
\end{tabular}

Table 5. Results of statistical analysis of release profiles obtained by means of difference (f1) and similarity (f2) coefficients in the range of 0-360 $\mathrm{min}$.

\begin{tabular}{|c|c|c|c|}
\hline \multirow{2}{*}{$\begin{array}{c}\text { Formulation } \\
\text { F-A } \\
\text { (reference) }\end{array}$} & F-B & F-C & F-D \\
\cline { 2 - 4 } & \multicolumn{3}{|c|}{ Release profiles are considered similar when $\mathrm{f} 1<15$} \\
\cline { 2 - 4 } & 48.94 & 27.41 & 12.12 \\
\cline { 2 - 4 } & \multicolumn{2}{|c|}{ Release profiles are considered similar when $\mathrm{f} 2>50$} \\
\hline
\end{tabular}

Table 6. Parameters of fitting mathematical models to the data of folic acid release in phosphatic buffer of $\mathrm{pH}=7.4$.

\begin{tabular}{|c|c|c|c|c|c|}
\hline $\begin{array}{c}\text { Kinetic } \\
\text { model }\end{array}$ & $\begin{array}{c}\text { Statistical } \\
\text { parameter }\end{array}$ & $\begin{array}{c}\text { Formulation } \\
\text { F-A }\end{array}$ & $\begin{array}{c}\text { Formulation } \\
\text { F-B }\end{array}$ & $\begin{array}{c}\text { Formulation } \\
\text { F-C }\end{array}$ & $\begin{array}{c}\text { Formulation } \\
\text { F-D }\end{array}$ \\
\hline \multirow{3}{*}{ Zero-order } & $\mathrm{R}^{2}$ & 0.8154 & 0.7435 & 0.8950 & 0.7470 \\
& RMSE & 9.4331 & 9.6388 & 20.4142 & 8.2273 \\
& AIC & 95.6941 & 259.9147 & 96.7339 & 107.8446 \\
\hline \multirow{3}{*}{ First-order } & $\mathrm{R}^{2}$ & 0.9899 & 0.8672 & 0.8982 & 0.9723 \\
& RMSE & 4.4482 & 7.4607 & 9.8025 & 4.7423 \\
& AIC & 76.1490 & 243.5211 & 80.5949 & 91.3165 \\
\hline
\end{tabular}

Table 7. Pharmacokinetic parameters of folic acid release from the test formulations.

\begin{tabular}{|c|c|c|c|}
\hline $\begin{array}{c}\text { F-A } \\
\text { (reference) }\end{array}$ & F-B & F-C & F-D \\
\hline \multicolumn{4}{|c|}{ Constant release rate $k\left[\mathrm{~min}^{-1}\right]$} \\
\hline 0.0717 & 0.0148 & 0.0187 & 0.0555 \\
\hline \multicolumn{4}{|c|}{ Half-lives of release $t_{50 \%}[\mathrm{~min}]$} \\
\hline 9.67 & 46.82 & 37.06 & 12.48 \\
\hline 580.326 & Area under the curve $A U C_{0-6 h}[\% * \mathrm{~h}]$ \\
\hline
\end{tabular}




\section{RESULTS}

Physicochemical characteristics of the powder mixtures are shown in Table 2, whereas morphological parameters of the references tablets are provided in Table 3.

The powder mixture used to make the reference tablets (formulation F-A) was characterized by average cohesiveness $(\mathrm{HR}=1.23)$ and good flowability $\left(\mathrm{I}_{\text {Carr }}=18.75\right)$ (16). The reference tablets (Formulation F-A) have met the standards and requirements of the Polish Pharmacopoeia X.

Quality assessment of the selected folic acid formulations was made based on the analysis of disintegration times and pharmaceutical availability of the active ingredient. The results of tablet disintegration times are presented in Table 4.

The results show that only the formulations FA (reference), F-B and F-D disintegrate in less than $15 \mathrm{~min}$, while $\mathrm{F}-\mathrm{C}$ in over $15 \mathrm{~min}$.

For dissolution testing evaluation of folic acid, phosphatic buffer of $\mathrm{pH}=7.4$ was used. Folic acid belongs to the group of water-soluble vitamins: $0.0016 \mathrm{mg} / \mathrm{g} \mathrm{H}_{2} \mathrm{O}$ in $298 \mathrm{~K}$ (17). Its solubility depends significantly on the $\mathrm{pH}$ value. At $\mathrm{pH}=7.0$ it is 183 times higher than at $\mathrm{pH}=1.0$ (18). In addition, folic acid is hydrolyzed to monoglutamate by the GCP2 enzyme (glutamate carboxypeptidase II) at $\mathrm{pH}$ = 6-7 before being absorbed into the intestine (19).

Based on the performed analyses and using the "Statistica Pharmaceutical Kit: Release Profiles", reports were generated containing data sheets, descriptive statistics, and a graphical comparison of release profiles (Fig. 1).

After $60 \mathrm{~min}$, the following amounts of folic acid are released from the test formulations: A $100 \%, \mathrm{~B}-45 \%, \mathrm{C}-63 \%$, D - 94\%, whereas the total amount of released folic acid is as follows: A $100 \%$ (after $60 \mathrm{~min}$ ), B - 75\% (after $360 \mathrm{~min}$ ), C 100\% (after $180 \mathrm{~min}$ ), D - 95\% (after $60 \mathrm{~min}$ ).

The profiles of folic acid release from the formulations were compared by means of $\mathrm{f} 2$ similarity and $\mathrm{f} 1$ difference coefficients (Table 5).

The determined values of $\mathrm{f} 1$ and $\mathrm{f} 2$ provided in Table 5 indicate that the release profiles of the analyzed formulations show no similarity.

The release of folic acid from all the test formulations is in accordance with the first order kinetics (Table 6). Pharmacokinetic parameters of release are shown in Table 7.

It has been demonstrated that the highest value of $\mathrm{k}$ and the lowest $\mathrm{t}_{50 \%}$ are obtained for the formulation F-A, while the lowest $\mathrm{k}$ and the highest $\mathrm{t}_{50 \%}$ for $\mathrm{F}$-B. Folic acid is released most rapidly from the formulation $\mathrm{F}$-A, on average about 5 times faster than from B, 4 times faster compared to $\mathrm{C}$ and 1.5 times faster compared to $\mathrm{D}$. The area under the folic acid release curve is the largest for the formulation F-A, nearly 1.5 times greater compared to F-B.

\section{DISCUSSION}

Effective folic acid pharmacotherapy can be provided by the formulations F-A and F-D. Similar

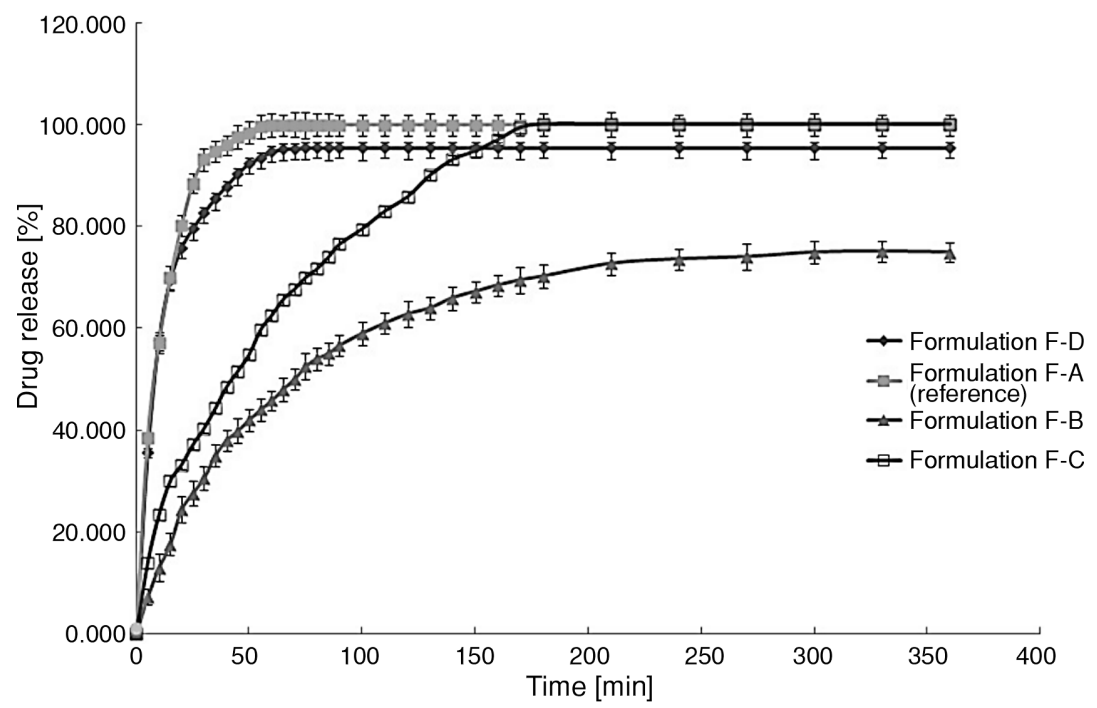

Figure 1. Graphical comparison of the profiles of folic acid release from the test formulations. Each value represents the mean \pm SD $(n=$ 12). The release profile of the formulation F-A (reference) is significantly different from the profiles of F-B, F-C, F-D ( $p=0.05)$ 
results were obtained by Hoag et al. when investigating the pharmaceutical availability of eleven formulations containing folic acid. Three of them complied with the standard, while only $25 \%$ of folic acid was released from two of the analyzed formulations (20). Similar results were obtained by Giebe (21), who tested seven folic acid formulations. Only three formulations showed proper in vitro availability of the active substance. A similar situation was observed in Great Britain (22). Only two of the eleven formulations met the release standards set forth in the British Pharmacopoeia (BP).

It has been found that the presence of starch, sorbitol and glucose (F-A) as well as lactose and starch (F-D) determines the optimal folic acid release time (F-A - 100\% after 60 min, F-D - 95\% after 60 min). The formulations F-B and F-C contain cellulose which lowers folic acid release, extends the disintegration time ( $\mathrm{F}-\mathrm{C}>15 \mathrm{~min})$ and active substance release time (F-B - 75\% after $360 \mathrm{~min}$ ) (23).

\section{CONCLUSION}

It has been found that formulations $\mathrm{A}$ and $\mathrm{D}$ have a half-life of 10 minutes and high pharmaceutical availability of folic acid.

\section{REFERENCES}

1. Kapka-Skrzypczak L., Niedźwiecka J., Skrzypczak M., Wojtyła A.: Med. Og. Nauk Zdr. 18, 65 (2012).

2. Brito A., Hertrampf E., Olivares M., Gaitán D., Sánchez H. et al.: Rev. Med. Chil. 140, 1464 (2012).

3. Etheredge A.J., Finnell R.H., Carmichael S.L., Lammer E.J., Zhu H. et al.: Am. J. Med. Genet. A. 158, 2439 (2012).

4. Kłaczkow G., Anuszewska E.L.: Acta Pol. Pharm. 63, 391 (2006).

5. Frankenburg F.R.: J. Clin. Psychiat. 70, 767 (2009).
6. Huo Y., Li J., Qin X., Huang Y., Wang X. et al.: JAMA. 7, 1325 (2015).

7. Jarosz M.: Nutritional standards for the Polish population - amendment, Food and Nutrition Institute, Warsaw 2012.

8. Marczyński Z., Fornal M.E., Jambor J., Zgoda M.M.: Herba Pol. 62, 66 (2016).

9. Linka W.A., Wojtaszek I., Zgoda M.M., Kołodziejczyk M.K.: Polim. Med. 45, 73 (2015).

10. Matias R., Ribeiro P.R.S., Sarraquça M.C., Lopes J.A.: Anal. Methods. 6, 3065 (2014).

11. Food and Drug Administration, Guidance for Industry: Dissolution Testing of Immediate, Release Solid Oral Dosage Forms. U.S. Department of Health and Human Services 1997.

12. Iwaniec M., Popieluch M.: Świat Przem. Farm. 5, 23 (2008).

13. Mendyk A., Jachowicz R.: Expert Syst. Appl. 32, 1124 (2007).

14. Costa P., Lobo J.M.S.: Eur. J. Pharm. Sci. 13, 123 (2001).

15. Saifullah M., Yusof Y.A., Chin N.L., Aziz M.G., Mohammed M.A.P, Aziz N.A.: J. Food Eng. 178, 60 (2016).

16. Ruszkowska M., Palich P.: Inż. Ap. Chem. 52, 83 (2013).

17. Younis I.R., Stamatakis M.K., Callery P.S., Meyer-Stout P.J.: Int. J. Pharm. 367, 97 (2009).

18. Wu Z., Li X., Hou C., Qian Y.: J. Chem. Eng. Data. 55, 3958 (2010).

19. Kapka-Skrzypczak L., Niedźwiecka J., Skrzypczak M., Wojtyła M.: Med. Og. Nauk. Zdr. 18, 65 (2012).

20. Hoag S.W., Ramachandruni H., Shangraw R.F.: J. Am. Pharm. Assoc. (Wash). NS37, 397 (1997).

21. Giebe K., Counts C.: Adv. Ther. 17, 179 (2000).

22. Sculthorpe N.F., Davies B., Ashton T., Allison S., McGuire D.N. et al.: J. Public Health. Med. 23, 195 (2001).

23. Kołodziejczyk M., Zgoda M. M.: Polim. Med. 42, 5 (2012).

Received: 16.06. 2017 